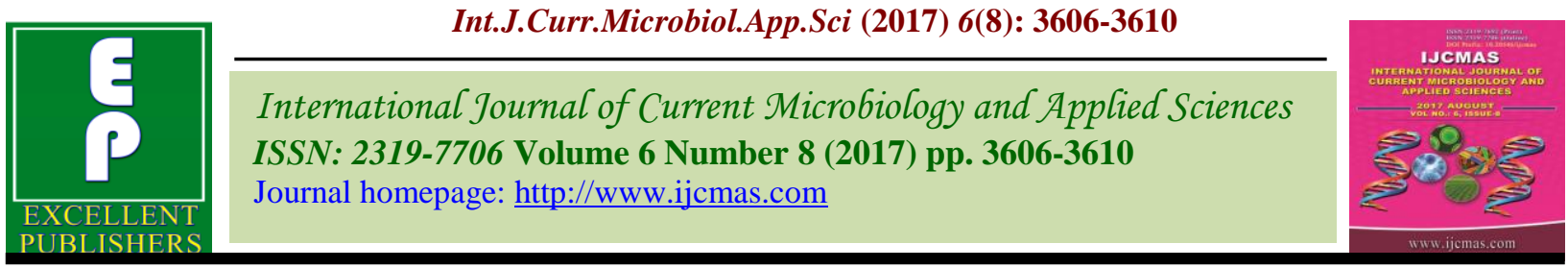

Review Article

https://doi.org/10.20546/ijcmas.2017.608.433

\title{
Prime-Ome: A Molecular Approach towards Defence Mechanisms
}

\author{
K.G. Kanjariya ${ }^{1} *$ and A. Parihar $^{2}$ \\ ${ }^{1}$ Department of Genetics and Plant Breeding, ${ }^{2}$ Dept. of Agricultural Biotechnology, \\ AAU, Anand, Gujarat, India \\ *Corresponding author
}

\begin{tabular}{|c|c|}
\hline & $A B S T R A T$ \\
\hline Keywords & \multirow{4}{*}{$\begin{array}{l}\text { Plants are constantly exposed to stressful situations due to changing environmenta } \\
\text { conditions or through their contact with numerous pests and pathogenic microorganisms } \\
\text { Plants have evolved various strategies to defend themselves against these stresses. Plan } \\
\text { responses to these stresses are complex and involve numerous physiological, molecular } \\
\text { and cellular adaptations. These defensive traits may be naturally occurring or artificially } \\
\text { selected through crop breeding, including introduction via genetic engineering. Such an } \\
\text { interaction between both types of stress points to a crosstalk between their respective } \\
\text { signaling pathways which may be synergistic and/or antagonistic and include among } \\
\text { others the involvement of phytohormones, transcription factors, kinase cascades, anc } \\
\text { reactive oxygen species (ROS). These include systematic acquired resistance (SAR) } \\
\text { induced systematic resistance (ISR) the resistance provided by symbiotic fungi, b } \\
\text { aminobutyric acid-induced resistance (BABAIR) and wound-induced resistance. }\end{array}$} \\
\hline $\begin{array}{l}\text { Pest, Stress, } \\
\text { Molecular, } \\
\text { Resistance, } \\
\text { Defence. }\end{array}$ & \\
\hline Article Info & \\
\hline $\begin{array}{l}\text { Accepted: } \\
\text { 27 June } 2017 \\
\text { Available Online: } \\
10 \text { August } 2017\end{array}$ & \\
\hline
\end{tabular}

\section{Introduction}

Plants exhibit a wide diversity of defensive traits and strategies to protect themselves from damage by pests and disease. Plants can be primed to respond faster and more strongly to stress and multiple pathways, specific for the encountered challenge, are involved in priming. As early as 1933, priming called 'sensitization' at the time, was wide accepted to be the pivotal phenomenon in systematic plant immunity (Chester, 1933). This adaptability of priming makes it difficult to pinpoint an exact mechanism: the same phenotypic observation might be the consequence of unrelated underlying events. Although some of these strategies are constitutive, i.e. present at all times, others are induced only in response to herbivore feeding or pathogen infection.
Recently, details of the molecular aspects of establishing a primed state and its transfer to offspring have come to light. Recent evidence shows that a combination of abiotic and biotic stress can have a positive effect on plant performance by reducing the susceptibility to biotic stress. Although some of these strategies are constitutive, i.e. present at all times, others are induced only in response to herbivore feeding or pathogen infection. Advances in techniques for detection and quantification of elements spanning the fields of transcriptomics, proteomics, and metabolomics, together with adequate bioinformatics tools, will soon allow us to take a holistic approach to plant defence. While these traits can have obvious and direct 
impacts on herbivorous pests, many have profound effects on higher trophic levels, including the natural enemies of herbivores. Multi-trophic effects of host plant resistance have the potential to influence, both positively and negatively, biological control. Plant defence traits can influence both the numerical and functional responses of natural enemies; these interactions can be semichemically, plant toxin, plant nutrient-, and/or physically mediated. Host plant resistance and biological control are two of the key pillars of integrated pest management; their potential interactions, whether they are synergistic, complementary, or disruptive, are key in understanding and achieving sustainable and effective pest management. Priming has now proven true as a critical process in various types of systematic plant immunity (Conrath et al., 2002, 2006, 2009; Jung et al., 2009). This review aims at giving an insight into cross-tolerance between abiotic and biotic stress, focusing on the molecular level and regulatory pathways.

\section{Priming}

It is the induction of a physiological state that enables cells to respond to very low levels of a stimulus in a more rapid and robust manner than non-primed cells. In plants, priming plays a role in defence ('defence priming') and seed germination ('seed priming').

\section{Primed state}

It is the physiological state of a plant that has been subjected to priming. Usually starts on exposure of such a plant to a challenging stress.

\section{Prime-ome}

It is the entire set of messenger RNA (mRNA) molecules of transcripts, proteins and metabolites produced or modified by an organism or a system during the different stages in priming of plants.

\section{Prime-omics}

It is the totally of transcriptional, proteomics and metabolic data available to describe the priming of plants or it is the study of primeome.

\section{Systematic acquired resistance (SAR)}

Type of systematic, broad-spectrum immunity in plants. Systematic acquired resistance is induced by local contact with a MAMP (Micro-Associated Molecular Pattern), or effector and depends on the plant hormone salicylic acid.

\section{Induced systematic resistance (ISR)}

Type of systematic, broad spectrum immunity in plants, Induced systematic resistance is elicited by colonization with selected strains of non-pathogenic, plant growth-promoting rhizobacteria and depends on the plant hormones ethylene and jasmonic acid.

\section{The priming process consists of three clear stages}

\section{Priming phase/Pre-challenge primed state}

This phase lies between the perception of the priming cue and the first exposure to future stress. During this time slot the plant generate and store information that will enable it to deploy faster and/or more accurate response to stress.

\section{Post-challenge primed state}

This phase starts with the exposure to a stress or challenge by the plant. In Primed plants, cellular defence response is not activated 
directly by the priming agent but are memorized and expressed in an accelerated manner after perception of a second biotic or abiotic stress signal. During this time slot the plant has strong up or down regulation of gene activity that will enable it to deploy faster and/or more accurate response to stress.

\section{Transgenerational primed state}

Priming for enhanced resistance also extends to next generations i.e. the progeny of primed parental plants shows resistance to the stress against which have been primed.

\section{Prime-omics in defence against pathogens and pest}

\section{Bacteria}

Vogel et al., (2013) observed the accumulation of various primary and secondary metabolites in tobacco when infected with Pseudomonas syrigaepv. tabaci (Pstb) reported that exogenous application of Pipeccolic acid prime tobacco plants to infection by Pstb and hypersensitive cell death-inducing $P$. syringaepv. maulicola.

\section{Oomycetes}

Burra et al., (2014) studied the transcriptome of Solanum tuberosumcv. Desiree and characterized the secretome by quantitative proteomics after foliar application of the protective agent phosphite and found that multiple defence pathways are rapidly induced by phosphite treatment that causes heightened defence leading to enhanced resistance after pathogen infection in local tissue.

\section{Fungi}

Molitor et al., (2011) reported that barley plants which are more resistant to Blumeriagra minis due to
Piriformosporaindica root colonization, 22 transcripts, including those of pathogenesis related genes and genes encoding heat-shock proteins were differentially expressed.

\section{Nematode}

Vos et al., (2013) using suppression subtractive hybridization ( $\mathrm{SSH}$ ) observed that plant genes responsible for secondary and hormone metabolism and defence and upregulated in tomato roots (Solanum lycopersicum $c v$. Marmande) pre-colonized by the AMF Glomus moose after 12 days of soil inoculation with $M$. Incognita juveniles.

\section{Arthropods}

Direct priming can be achieved through either chemical or natural stimuli. Natural stimuli can stem from arbuscular mycorrhizae, nonpathogenic rhizobacteria or various arthropod cues such as oviposition or insect wounding. In priming against arthropods, abscisic acid $(\mathrm{ABA})$ is key regulator that activates defences co-ordinately with jasmonic acid (JA) and systemin-dependent signalling. Mao et al., (2013) reported that upon leaf folder attack, rice plants subjected to $\mathrm{Si}$ pre-treatment exhibited enhanced defence responses relative to untreated controls, including higher levels of JA accumulation; increased levels of transcripts encoding defence markers genes and elevated activities of peroxidase, polyphenol oxidase and trypsin protease inhibitor.

Indirect defence priming is more diverse. It involves the enhancement of defence response in neighbouring plants and also more efficient attraction of predators. Primed defences in surrounding plants activate ocymene synthase (OS), which catalyses the accumulation of bocimone. Vieira et al., (2012) observed that the secondary metabolites cis-jasmone activates the metabolic pathway that produced volatile organic compounds attractive to 
natural enemies and sometimes, repellent to herbivores and reported that spraying cisjasmone increased number of Scelionidae egg parasitoids of stink bugs in soybean plots.

\section{The costs and benefits of priming}

Although priming is an integral part of both ISR and SAR, only priming has no or minimal negative impact on the host plants energy status. Primed plants deploy their defence repertoire only during pathogen attack and not in a constitutive manner. Induction of direct defences is often associated with high physiological costs that can minimize the benefits of the enhanced protection. By contrast, primed plants show almost equal protection levels but suffer from considerably lower fitness costs, these makes priming -based approaches valuable for crop protection strategies.

In conclusion, prime-omics is an integrated approach for defence priming which involves different techniques spanning the fields of transcriptomics, proteomics and metabolomics together which adequate bioinformatics tools. Various novel approaches can help plants to resist under combinatorial stress. The "Omics" technology is one of these approaches. Transcriptomics, proteomics, and metabolomics have revealed plant responses under stress and their underlying mechanisms and point to potential target genes, proteins or metabolites for inducing tolerance and improve plant responses. Although complete genome sequences are available for an increasing number of crop and model plants, in comparison, protein and metabolite databases are still rather incomplete, hence complicating the task of integrating all observations. Additionally, different plant species or even cultivars may behave differently, plant responses are also often organ-dependent, and results obtained with whole plants may be misleading. Primed plants show faster and stronger defence responses when subsequently challenged by microbes, insects or abiotic stress and this is frequently linked to development of local and systemic immunity and stress tolerance. The availability of rapidly growing transcriptomic, proteomic and metabolic datasets, the primeome, describing the state of primed plants will allow us to define the elements that are responsible for the capacity of certain plants to be more efficiently primed than others and thus, to exploit this knowledge by introducing these traits in to crop plants.

\section{References}

Balmer, A., Pastor, V., Gamir, J., Flors, V. and Mauch-Mani, B. 2015. Trends Plant Sci., 20: 443-452.

Burra, D.D., Berkowitz, O., Hedley, P.E., Morris, J., Resjo, S., Levander, F., Liljeroth, E., Andereassson, E. and Alexandersson, E. 2014. BMC Plant Biol., 14: 254.

Chesterm, K.S. 1933. Rev. Biol., 8: 275-324.

Conrath, U., Pieterse, C.M.J. and Mauch, Mani, B. 2002. Trends in Plant Sci., 7: 210-216.

Conrath, U., Beckers, G.M.J., Flors, V., Garcia-Agustin, P., Jakab, G., Mauch, F., Newmean, M.A., Piesterse, C.M.J., poinssot, B., Pozo, M.J. Pugin, A., Schaffrath, U., Ton, J., Wendehenne D., Zimmerli, L. and Mauch-Mani, B. 2006. Mol. Plant Microbe Interact., 19: 1062-1071.

Conrath, U. 2009. Adv. Botanical Res., 51: 361-395.

Jung, H.W., Tschaplinski, T.J., Wang. L., Glazebrook, J. and Greenberg, J.T. 2009. Sci., 324: 89-91.

Mao, Y., Song, Y., Long, J., Wang, R., Baerson, S.R., Pan, Z., Zhu-Salman, K., Xie, J., Cai, K., Luo, S. and Zeng, R. 2013. PNAS, E3631-E3639.

Martin Heil. 2014. New Physiologist, 204: 
297-306.

Molitor, A., Zajic, D., Voll, L.M., PonsKuhnmann, J., Samans, B., Kogel, K.H. and Waller, F. 2011. Barley Leaf Transcriptome and Metabolite Analysis Reveals New Aspects of Compatibility and Piriformosporaindica-Mediated Systemic Induced Resistance to Powdery Mildew. MPMI, 24(12): 14271439.

Vogel-Adghough, D., Stahl, E., Navarova, H., and Zeier, J. 2013. Pipecolic acid enhances resistance to bacterial infection and primes salicylic acid and nicotine accumulation in tobacco. Plant
Signal Behav., 8(11): e26366.

Vos, C., Schouteden, N., van Tuinen, D., Chatagnier, O., Elsen, A. and De Waele, D. 2013. Mycorrhiza-induced resistance against the root-knot nematode Meloidogyne incognita involves priming of defense gene responses in tomato. Soil Biol. Biochem., 60: 45-54.

Vieira, A., Talhinhas, P., Loureiro, A., Thurich, J., Duplessis, S., Fernandez, D., Silva, M., Paulo, O.S. and Azinheira. H.G. 2012. Eur. J. Plant Pathol., 133: 261-277.

\section{How to cite this article:}

Kanjariya, K.G., and Parihar, A. 2017. Prime- Ome: A Molecular Approach towards Defence Mechanisms. Int.J.Curr.Microbiol.App.Sci. 6(8): 3606-3610. doi: https://doi.org/10.20546/ijcmas.2017.608.433 